\title{
Técnicas de representación digital aplicadas a los proyectos arquitectónicos en Nuevo León, México
}

Fecha de recepción : 2021-04-14 • Fecha de aceptación: 2021-06-30 • Fecha de publicación: 2021-09-10

Raymundo Alberto Portillo Ríos

Universidad de Monterrey, México

raymundo.portillo@udem.edu

https://orcid.org/0000-0001-7575-4956

\section{Resumen}

Una de las ramas de la arquitectura que más se ha visto impactada por la digitalización es la representación, entendida esta como tarea esencial en el proceso de diseño, creación y comunicación del proyecto arquitectónico, realizada por medio de herramientas digitales que progresivamente han venido ganando terreno en el quehacer técnico y profesional de la construcción. El presente trabajo analítico descriptivo, de enfoque cuantitativo, se basó en analizar las técnicas digitales aplicadas para la representación de los proyectos arquitectónicos en Nuevo León, México. Su importancia radica en lo relevante que resulta la actividad de la industria del diseño y la construcción, para la económica regional y nacional. Entre los resultados del estudio resalta el uso privilegiado de los dibujos digitales en 2D, por parte de los arquitectos informantes, ya que estos son considerados como expresiones originarias del diseño arquitectónico; en igual medida le siguen los dibujos digitales en 3D de representación formal y volumétrica. Cómo técnicas complementarias se encuentran el uso y edición digital de imágenes y videos, así como también las técnicas de fabricación digital. Mientras que la realidad virtual, y la realidad aumentada, no se consideraron como parte esencial de la representación digital del proyecto arquitectónico. 


\begin{abstract}
Architectural drawing is one of the fields most influenced with the digital transition. Architects consider digital tools as an essential instrument in all the steps to create a project, starting for the design process, planning and to communicate the final result. Digital drawing has been increasing popularity in the construction area. This article is a descriptive and analytical work with quantitative approach, which has been based on analyzing digital drawing techniques applied to represent architectural projects in Nuevo León, México. Its importance lies in the relevance of the software and how to develop the activities related to the design industry, construction and also for the regional economy growth. The research was based on a survey directed to the architects of the region. The results of the study remark the preference in 2D use for digital drawings because these are considered as original expressions of architectural design . In equal measure 3D digital drawings are used for formal and volumetric representation. Complementary techniques include the use of software for digital editing of images and videos. The digital fabrication techniques are used as well. By other hand, virtual reality and augmented reality are not considered as an essential part of digital communication for the architectural project.
\end{abstract}

Keywords: digital drawing techniques, architecture, drawing, architectural projects, digital tools, digital drawing. 


\section{Introducción}

El proyecto arquitectónico como documento, es la suma de determinaciones y representaciones gráficas, así como de memorias escritas de la obra o edificio que desea ser construido; este sirve de referente y documento base para el estudio y concreción del proceso a materializarse, así como para su administración, legalización y revisión, según sea su emplazamiento.

El proyecto arquitectónico, debe, además, justificar las necesidades solventadas, así como dar respuestas a las soluciones propuestas, indicando especificaciones, costos y procesos (Muñoz, 2018). Por lo que toda la arquitectura se concibe, se produce y se manifiesta, como un proyecto en el que se aplica la representación como medio y comunicación.

Estas representaciones gráficas de la arquitectura son ahora aplicadas mediante escenarios o herramientas digitales, lo cual ha constituido el reforzamiento del cambio de paradigma gráfico que comentan Montaner (2015) y Lopis (2018a).

Oliva (2016, p.10) plantea que dicho cambio de paradigma gráfico, sobrevenido por la aplicación de las técnicas digitales, constituye más que un mero relevo instrumental de herramientas; ya que, los métodos digitales "intentan aplastar por completo todo sistema anterior de ideación, dibujo, desarrollo y comunicación de la propuesta arquitectónica".

Llopis (2018a, p. 180) plantea otra consecuencia, y es la de generar una imagen gráfica asentada sobre los principios de la simulación. "Un tránsito conceptual que transforma profundamente los propios principios teóricos del dibujo arquitectónico" tal y como se ha considerado hasta la actualidad, sobre todo en cuanto a la relación que existe entre la realidad y la representación arquitectónica.

De lo antes dicho se entiende que las técnicas digitales, aplicadas a la representación de la arquitectura, constituyen uno de los cambios más significativos en cuanto al quehacer del proyecto de diseño y de su construcción.

Sin embargo, dichas técnicas no son aprovechadas ni conocidas a profundidad por buena parte de la industria de la construcción, de acuerdo con los resultados de la encuesta, realizado por el grupo KPMG International (2016), donde se indica que el sector de diseño y construcción sigue siendo muy conservador en cuanto al uso y adaptación de las tecnologías digitales, reflejando que:

- Solo $8 \%$ de las empresas del mundo utilizan tecnologías digitales de avanzada.

- Ni las firmas de ingeniería y construcción, ni los propietarios de proyectos, aprovechan por completo los volúmenes de datos a su alcance; la mayoría de los encuestados ( $72 \%$ global, $82 \%$ México) no utilizan el procesamiento analítico de estos, ni la obtención de data a tiempo real sobre los proyectos en ejecución.

- Además, se indica que $64 \%$ de los constructores y $73 \%$ de los propietarios de proyectos se posicionaron como "seguidores de la industria" en cuanto al uso de dichas tecnologías, es 
decir, sólo se aplican cuando están ampliamente difundidas en el mercado e invierten en desarrollo e innovación (KPMG, 2016).

Por su parte, la situación en México es igual que en el resto del mundo, debido a la diversidad de empresas y a sus alcances en cuanto al manejo de proyectos de mayor o menor escala, bien sean de carácter público o privado.

Dicho retraso tecnológico se da, a pesar de ser este uno de los sectores más importantes de la economía nacional, como reflejan los datos de la Cámara Mexicana de la Industria de la Construcción (CEESCO, 2018), donde se señala que esta constituye 10\% de contribución al PIB nacional, convirtiéndose además como el tercer empleador más importante del país.

Puntualmente, el mismo organismo señala que la situación de la actividad constructiva para el año 2018 y 2019 (antes de la pandemia de COVID - 19), presentó una contracción de -1,3\%, siendo el sub sector de las ingenierías civiles (obras públicas de envergadura) el más afectado con una reducción de $10 \%$ de sus actividades, lo cual impacta directamente en el desarrollo de otras sub industrias de servicios y manufacturas asociadas directa o indirectamente a la construcción.

Entre las recomendaciones presentadas por el Centro de Estudios Económicos del Sector de la Construcción (CEESCO), para revertir dicha situación, está la de "aumentar la capacitación del personal en áreas como: desarrollo, innovación y progreso tecnológico” (CEESCO, 2018, p. 7). Dando por sentado el poco personal capacitado en torno a las nuevas tecnologías digitales disponibles en el mercado.

Por ello se hizo necesario estudiar las tecnologías digitales aplicadas a la representación del proyecto arquitectónico en Nuevo León, México, ya que constituye un área prioritaria de oportunidad para el desarrollo de la industria del diseño arquitectónico y la construcción, el cuál ocupa una posición clave en la economía regional y nacional.

\subsection{Representación arquitectónica}

Sainz (2009, p. 25) desarrolla la teoría del dibujo arquitectónico, entendiendo a la representación, como el "sistema gráfico" de comunicación del proyecto; partiendo de la premisa que los objetos arquitectónicos por su complejidad y estudio, han de realizarse a través de procedimientos y dimensiones específicas de la arquitectura, "lo que induce a pensar que la representación gráfica de tales objetos ha de exigir unos procedimientos distintos a los de otras disciplinas".

En la misma línea, Ching (2016, p. 29), asocia el concepto de dibujo y representación, como actividad primordial del profesional de la arquitectura, a fin de comunicar y transmitir las ideas del edificio representado. Dice al respecto: "la función principal del dibujo arquitectónico es la representación de formas, construcciones y espacios tridimensionales sobre una superficie bidimensional. A lo largo del tiempo se han desarrollado tres sistemas: los dibujos de vistas múltiples, las axonometrías y las perspectivas". 
Según el autor, estos sistemas de representación "constituyen un lenguaje gráfico formal que se rige por una serie de normas coherentes. La comprensión de estas normas y las convenciones relacionadas con ellas es fundamental para poder crear dibujos arquitectónicos y saber interpretarlos" (Ching, 2016, p. 29).

Ambos autores, Sainz (2009) y Ching (2016), coinciden en entender la representación arquitectónica como un sistema de comunicación, como una técnica que permite la comprensión del objeto arquitectónico. La arquitectura se representa, se comunica, mediante un lenguaje gráfico, visual, con códigos particulares y específicos, entendidos y asumidos de manera universal.

Etchegaray (2015) también identificará a la representación arquitectónica como medio de comunicación, tomando en consideración su aplicación y manifestación en cada momento de su producción como proceso; indicando en su estudio tres momentos claves de su aplicación: en la concepción del proyecto, en la presentación o evidencia del mismo, y para su ejecución, como documento referente para su materialización.

Para Muñoz (2016), la representación de la arquitectura es lo mismo que la representación del proyecto arquitectónico, debido a que es la manera en cómo se cuenta y se transmite las ideas de la arquitectura, y, por ende, de esta en sus fases proyectuales.

Ching (2016, p. 44) coincide con el autor anterior, en afirmar que la representación es vital para transmitir las ideas del proyecto arquitectónico, el académico señala que en este se utilizan dibujos para transmitir su calidad espacial y visual. "En este caso, los dibujos de proyecto se centran en reflejar y mostrar con claridad el lleno y el vacío de formas y espacios, las relaciones de escala y proporción, y otras características importantes del espacio", que constituyen la esencia de la arquitectura como disciplina profesional, creadora de espacios y formas, construibles y amigables.

Por su parte, Pecoraio (2017, p. 5) señala que la representación arquitectónica "es necesaria "para la comprensión de los elementos y las relaciones que componen un proyecto (...) para la comunicación de sus contenidos entre todos los agentes que intervienen (...) para establecer y verificar las dimensiones dentro de los planos, para la correcta puesta en obra de los edificios".

\subsection{Técnicas de representación digital}

Se entiende entonces que todo proyecto arquitectónico se geste desde la representación, ya que hacer arquitectura es representarla, y dicho proceso de diseño, proyecto y construcción, es posible mediante la aplicación de diversas técnicas.

Oliva (2016, p. 18), las define como “(...) el conjunto de procedimientos, recursos, herramientas e instrumentos generales, así como a su manejo que sirve al efecto del dibujo, la representación y comunicación, pero también en muchas ocasiones al efecto de la ideación del proyecto de arquitectura o diseño".

De manera que el modo de comunicar, proyectar y hacer arquitectura, pasa necesariamente por la aplicación de una determinada técnica, la cual establece y determina todo el proceso desde su 
fase de ideación, proyección, representación y comunicación del hecho arquitectónico, en toda su complejidad y concreción.

Ching (2016, p.44) lo dice de manera más simplificada al enunciar que "los dibujos de proyecto transmiten la información con medios gráficos". De modo que asocia la técnica a los medios de dibujos empleados para la arquitectura.

Es tal la importancia de las técnicas de representación aplicadas en arquitectura, que Sainz (2009, p. 30), afirma que "la representación del espacio arquitectónico se ve restringida por las propiedades del medio gráfico en que se desenvuelve". Y de allí las implicaciones trascendentales del tipo de técnica usada para la generación de la arquitectura, bien sean estas analógicas o digitales.

Oliva (2016, p.18), define las técnicas de representación analógica como "los protocolos seguidos (geometría descriptiva y dibujo en sistema diédrico), y las herramientas de representación precedentes y de uso cotidiano por los arquitectos, a la revolución de la tecnología digital". Es decir, la técnica aplicada antes de la digitalización.

En sentido opuesto, la técnica de representación digital es "el procedimiento que se sirve del instrumental conjunto de hardware y software, utilizado para dicha producción, así como a su manejo en aras del dibujo 2D o 3D y la edición de imagen y vídeo durante el proyecto". (Oliva, 2016, p. 18).

De todo lo expresado, deviene lo que se conoce como la representación digital del proyecto arquitectónico, que como lo refiere Oliva (2016), son todos aquellos documentos gráficos acabados y producto del trabajo mediante las técnicas de representación digital, estos servirán "para la comunicación de la idea y del proyecto de arquitectura y diseño, y que por descontado forman parte de la documentación, pública o privada, del mismo" (Oliva, 2016, p. 18).

Etchegaray (2015) por su parte, habla del uso del medio digital como suporte de representación del proyecto arquitectónico, por lo que taxativamente no se referirá a técnicas digitales de representación, sino a medios digitales.

De la misma manera, Picon (2006) comenta sobre los medios digitales y digitalización de los procesos proyectuales de la arquitectura; diciendo al respecto que "la digitalización del diseño podría perfectamente parecer un mero avance de la técnica, un poder suplementario que se ha ofrecido al diseñador, pero que no afecta la naturaleza de su producción".

Ching (2016), por su parte, emplea el término de dibujo digital, más que como técnica, como proceso de creación, y por ello identifica sus ventajas con respecto a las técnicas analógicas que identificará como tradicionales; señalando dichos beneficios como: “...la posibilidad de experimentar con las modificaciones del proyecto, estudiar puntos de vista alternativos o probar técnicas de dibujo diferentes. Estas ventajas radican en la posibilidad de deshacer una acción o una serie de operaciones, o de guardar una versión de un dibujo mientras se trabaja en una copia y volver a la versión guardada si es necesario" (Ching, 2016, p. 41). 
Los autores Picon (2006) y Etchegaray (2015) determinan a los medios digitales como soportes o instrumentos para la representación de la arquitectura, asumiendo por decantado, que esta es una técnica en uso para el proyecto arquitectónico, y en esto último coinciden en lo planteado por Ching (2016), en ver la digitalización como una alternativa de la técnica de representación.

También Pecoraio $(2017$, p.5) se refiere al manejo de medios, instrumentos, y materiales para "comprender y representar el proyecto desde la fase de ideación hasta la fase de construcción".

Aunque sin dar el indicativo de digitales, el autor mencionado las mencionada como una "evolución de las técnicas y las herramientas de representación en el último siglo" que no solo ha transformado el aspecto gráfico y visual de la arquitectura "sino ha influido enormemente en el diseño de la arquitectura misma, introduciendo posibilidades proyectuales inéditas" (Pecoraio, 2017, p. 5).

Para el presente trabajo se asumió la propuesta teórica de Oliva (2016), ya que es la definición más completa y específica, por considerar dimensiones como dibujo 2D o 3D, la edición de imagen y las técnicas de vídeo, durante el proyecto. Estas serán las referencias a explicar.

\subsection{Dibujos en dos dimensiones 2D}

Son dibujos en base a proyecciones en dos dimensiones, o bidimensionales, también conocidas como ortogonales.

Ching \& Juroszek (2012) las incluye dentro de los dibujos con visión múltiple, indicando que son los que se conocen por plantas, alzados y secciones. De acuerdo con los autores, se caracterizan porque cada uno de ellos es una proyección ortogonal de un aspecto de un objeto formal (incluido el arquitectónico); las visiones ortogonales son abstractas, no concuerdan con la realidad visual; son una modalidad de representación conceptual que se fundamenta más en lo que se conoce sobre algo, que en cómo se ve desde un punto del espacio; y no hacen referencia al observador y, en caso de haberla, el mismo se encuentra en el infinito.

De manera muy escueta, Muñoz (2016, p.118) define estas representaciones como "dibujos a escala como plantas, alzados, secciones", no dando mayor detalle sobre ellas, sólo planteándolas como el primer modo de contar y comunicar el proyecto arquitectónico, identificándolas como "proyecciones diédricas".

Sin embargo, aporta un dato interesante al respecto, ya que señala que este tipo de dibujos son "instrumentos de control formal", y "verificación del diseño" que se propone en la actividad profesional (Muñoz, 2016, p. 38).

Es decir, asocia este tipo de proyecciones a la gestión y dirección del proyecto arquitectónico, al añadirle funciones de control y verificación. Es interesante también el inciso histórico que menciona Muñoz (2016, p. 154) sobre la aplicabilidad de este tipo de dibujos en arquitectura, señalando que "este sistema de concepción y representación del proyecto, a través de trazas y dibujos, se había ido desarrollando paulatinamente a lo largo de todo el siglo XVI, en el que «la 
serie de dibujos arquitectónicos con mediciones - planos, alzados y secciones- se convirtieron en el medio de comunicación entre el arquitecto y los obreros»".

De modo que la pertinencia y aplicabilidad de este tipo de representaciones en arquitectura, es de larga data, Oliva (2016) sostiene reiteradamente que este tipo de dibujos serán posibles también en el uso de las herramientas digitales aplicadas a la representación del proyecto arquitectónico.

Pecoraio (2017) coincide con Muñoz (2016) al identificar dichos dibujos como diédricos, como necesarios para conocer y representar cualquier objeto o forma, identificando planta, vistas (alzados) y secciones.

\subsection{Dibujo en tres dimensiones 3D}

Los dibujos en tres dimensiones o tridimensionales se caracterizan por mostrar la volumetría del objeto, añadiendo las tres referencias básicas de: altura, anchura y profundidad, conocidas y estudiadas ampliamente en la geometría analítica y descriptiva.

Ching \& Juroszek (2012, p. 120) entenderán dichas representaciones como proyecciones axonometrías y perspectivo, estos "ofrecen en una única imagen una o dos facetas de una estructura tridimensional". Su característica gráfica fundamental "es que en las axonometrías las líneas paralelas conservan esta condición, mientras que en las perspectivas convergen en los puntos de fuga", añade el autor.

Por su parte, Muñoz (2016) es más escueto en su explicación, y asocia este tipo de proyecciones a simples representaciones tridimensionales, sin dilucidar el tipo de técnica o vista empleado para obtenerlas, sostiene que las "axonometrías, perspectivas, fotomontajes, maquetas, infografías o cualquier otra simulación" son aquellas que hacen posibles la legibilidad de las determinaciones del proyecto, producidas sobre todo para aquellos que "no tienen la formación técnica adecuada para deducir de los planos técnicos la realidad del proyecto" (2016, p. 115).

Tanto Ching (2016), como Muñoz (2016), indican que los softwares de representación digital permitirán hacer elementos tridimensionales con mayor facilidad, gracias a las funciones de grupos y capas, lo cual constituye una de sus principales ventajas y por ende, una de sus características fundamentales.

\subsection{Edición de imágenes}

El tema de la imagen es basto y complejo en la representación arquitectónica, pues interviene en el postulado fundamental de la representación como imagen creada o diseñada de algo, que se identifica como objeto arquitectónico. Por eso señala Muñoz (2016, p. 120) que "en arquitectura, el dibujo es el pensamiento mismo del arquitecto; es la imagen presente de un edificio futuro".

Llopis (2018b, p. 281) desarrolla un interesante debate sobre la imagen en la arquitectura, y su banalización como parte del proyecto, por la incidencia de Internet y el consumo de esta como producto; lo refiere de manera enfática en el "mundo digital, en el que la imagen arquitectónica ha 
migrado del libro a la red, cohabita con imágenes digitales creadas para el cine, con la dinámica de percepción espacial de los videojuegos, y con los mundos dibujados del cómic".

Oliva (2016, p. 109) se refiere a la imagen vectorial, "generada desde software de delineación que da lugar a una representación gráfica, basada en descripciones geométricas que se rigen por un sistema cartesiano".

En este caso, el usuario que opera la herramienta tiene la posibilidad de reproducir muchas veces dicha representación, inclusive en diversas escalas, tamaños y proporciones, con más o menos detalles, para obtener así mediciones absolutas, precisas y exactas del elemento dibujado. "Es la representación fundamental de los programas C.A.D. y modeladores 3D”, puntualiza Oliva (2016).

El autor, refiriéndose a estas últimas, dice que el dominio de la técnica digital da mayores posibilidades de actuación en el área del diseño, ya que permite controlar el proceso de creación y el desarrollo de esa "imagen intencionada para que vaya más acorde con el pensamiento contemporáneo y pueda ser mucho más efectiva" (Oliva, 2016, p. 109).De manera que esta sea de gran ayuda para la comunicación del proyecto arquitectónico, tanto desde el punto de vista profesional, como comercial y social, desde la perspectiva de esta como mensaje.

\subsection{Edición de audio y videos}

Referido al uso de vídeos y elementos audiovisuales para la representación del proyecto arquitectónico, Muñoz (2016, p.119) lo describirá como un instrumento de comunicación, indicando que "el cine, el vídeo, el rendering o las animaciones pueden llegar a las cuatro dimensiones al introducir el movimiento en una realidad tridimensional" creada mediante el uso y aplicación del computador.

Oliva (2016) la incluirá dentro de las herramientas de las técnicas de representación digital de la arquitectura, haciendo la acotación de que los inicios de su aplicación, son controversiales, ya que sus orígenes no se centran en la comunicación del dibujo arquitectónico, o al menos no desde el punto de vista de este como producto de una disciplina profesional; pues el "primer diseño de espacio virtual se concibió no para un proyecto de arquitectura, sino para un videojuego" (2016, p.40) Aunque su uso se haya extendido a otras áreas del diseño, incluso más allá del estrictamente arquitectónico.

\subsection{Realidad virtual/aumentada}

Aunque muy ligado al punto anterior, pues también tiene como fundamento el manejo de la imagen y el vídeo, la llamada realidad virtual y realidad aumentada, son señaladas como parte de las técnicas de representación digital del proyecto arquitectónico, aplicadas como soporte de comunicación.

Navarro \& Fonseca (2017) comentan que esta manifiesta "una realidad de forma inmersiva, aislando en mayor o menor parte al usuario de su entorno", por lo que su característica primordial es situar a este en un entorno diferente, no real físicamente (llamado virtual). 
Mientras que en la realidad aumentada se "superpone dicha información en un dispositivo que permite situarse en dicho entorno real del usuario", es decir, no se pierde vista la realidad real del usuario, sino que, por las herramientas digitales, esta se superpone, se adapta, se añada a lo físicamente existente (Navarro \& Fonseca, 2017, p. 219).

Estas realidades virtuales sólo son posibles por "el avance tecnológico exponencial de los últimos años y la aparición de nuevos dispositivos", que han permitido, "disponer de móviles y tabletas con capacidad de procesar información multimedia" (Navarro \& Fonseca, 2017, p. 220) a grandes velocidades.

Por otra parte, Higuera et al. (2017, p.103) asocian a la realidad virtual un sentido de simulación hiperrealista de la arquitectura, llevándole a afirmar que esta "ofrece la posibilidad de generar representaciones arquitectónicas que generan la sensación de "estar ahí", aunque materialmente el objeto no exista en la realidad real, y por ende no sea físicamente tangible.

La realidad virtual genera entonces una simulación de la arquitectura, más que una representación de esta, y para ello “...dispone de multitud de medios, que han ido incorporándose y reciclándose a medida que la tecnología lo posibilitado. Desde los tradicionales dibujos y maquetas, hasta la fotografía, el vídeo, o los montajes. Actualmente, las constantes innovaciones en la informática aplicada a la simulación mediante modelos tridimensionales están convirtiendo la "Realidad Virtual", otrora una tecnología inabordable, en una herramienta habitual" (Higuera et al., 2017, p.103).

Vale destacarse en este punto la crítica que hace Picon (2006) sobre esta virtualización de la representación arquitectónica, según el autor, "el término virtual prácticamente irrumpe asociado a una acusación implícita de desmaterialización que opone declaradamente realidad virtual y realidad real" de la arquitectura. Ya que la materialidad asociada a la producción profesional del oficio es uno de los aspectos fundamentales de la arquitectura como objeto físico.

Es esa la diferencia entre arquitectura (edificio físico y material, construido) y proyecto de arquitectura (edificio proyectado, inmaterial, aunque visualizado en un entorno virtual), y de allí la crítica en cuanto al enfoque y los límites de la realidad virtual y la simulación en el campo profesional.

Rodríguez et al. (2016) responden a las críticas debatiendo que dominar los medios virtuales ofrece una singular libertad a la hora de proyectar y presentar una idea, la cual no debe considerarse como antagónica del dibujo a mano, sino más bien como una técnica más, como un complemento que puede resultar de gran ayuda en el proceso de diseño y de comunicación del proyecto arquitectónico.

Puntualizan que "de hecho, gracias al mundo virtual, se han podido llevar a cabo proyectos muy alejados de aquello que tradicionalmente se apoyaban en los conceptos euclidianos y que nos proporcionan una arquitectura de una gran diversidad y riqueza espacial" (Rodríguez et al., 2016, p. 453$)$. 
Garrell \& Guilera (2019, p.74) son más enfáticos y concisos, ya que la definen como la producción: "mediante programación informática un entorno que aparece a los ojos del usuario como real e inmerso en él, mediante el equipamiento hardware adecuado (gafas tridimensionales) y, optativamente, guantes y traje especial para sensaciones táctiles".

\subsection{Fabricación digital}

La fabricación digital es una técnica todavía en expansión y que tiene múltiples aplicaciones en diversas áreas, como señalan Ferrándiz et al. (2018), y uno de ellos es la arquitectura.

Por su parte, Frogheri $(2018$, p. 38) sostiene que esta "es parte de un sistema que recibe datos desde algo que los produce, en este caso una computadora, y los devuelve de otra forma, en este caso como materializaciones. Si consideramos la estructura básica de este sistema, no es difícil comprender que está compuesto por unos datos que entran en un dispositivo, que los recibe y eventualmente los traduce para devolverlos en otra forma".

Esa otra forma, producto de la digitalización, sea material o física, aunque en algunos casos también digital, a modo de metadatos, se transformará y se materializará, pasando de datos a objetos, y de allí el por qué esta es considerada como el pensar y hacer avanzados como técnica de diseño.

En la misma línea, Jorquera $(2017$, p. 5), señala que la fabricación digital va más allá de la simple digitalización de los procesos, ya que esta involucra un "amplio abanico de herramientas y conceptos: desde la precisión nanométrica a máquinas capaces de la auto-replicación, hasta lenguajes de programación". De modo que su impacto en el ámbito social y profesional es amplio e incuestionable.

Similar a la idea expresada por Frogheri (2018), Jorquera (2017, p. 6) dirá que la fabricación digital (a la que denomina revolucionaria) se fundamenta en una idea simple: "convertir la información en cosas y las cosas en información".

A su vez, Robles (2016, p. 3), con una visión más holística, define la fabricación digital como "un método para dirigir un proceso de manufactura con el uso de datos digitales que controlan los procesos de fabricación, respaldándose en maquinaria y herramienta controlada por computadora para construir o cortar pieza".

La autora señalada hará además un inciso muy pertinente en cuanto al tema y la práctica profesional del diseño, y la construcción de la arquitectura, esta afirmará que la fabricación digital: "ha permitido la reconexión del arquitecto con la materia, ya que desde el proceso de diseño se debe pensar en el material adecuado, y la experimentación permite un estudio de las propiedades de éste para ser trabajado con cierta máquina" (Robles, 2016, p. 3).

También Abondano (2018, p. 40) refiere dicho aspecto, indicando que "los procesos CAD/CAM facilitan que el arquitecto sea partícipe del proceso de fabricación". Por ende, este asume nuevos riesgos, en cuanto al diseño, ya que debe replantearse el proceso, no solo como diseño, sino 
más allá como "gestión, fabricación o construcción del edificio, a partir de las nuevas tecnologías digitales".

Robles (2016, p. 5) afirma que existen varias técnicas que pueden ayudar al diseñador a concebir, desde la etapa de diseño, el proceso de construcción de las piezas que integrarán el modelo y, dependiendo de la geometría, hay técnicas que se adecuarán más o que en combinación a otra permitirán su construcción física.

La escogencia o preferencia de esta dependerá de los resultados esperados a obtener, o bien de la habilidad del diseñador y su equipo en familiarizarse con las tecnologías y herramientas necesarias para aplicarlas a cada proyecto; estas serían: seccionado, mosaico, doblez, contorneado y moldeado.

\section{Metodología}

Todo el trabajo se desarrolló siguiendo el método racional de análisis deductivo, el cual como indican Hernández et al. (2014), es propio de los estudios con enfoque cuantitativos. El tipo de investigación fue analítico, con diseño no experimental, transaccional.

El objetivo general versó sobre analizar las técnicas de representación digital aplicadas en la representación del proyecto arquitectónico en Nuevo León, México, para ello se plantearon objetivos específicos que respondieron a identificar las técnicas de representación digital utilizadas, así como a señalar los motivos de su uso; además de describir sus principales características.

Para ello se diseñó y aplicó un instrumento de recolección de datos cerrado, con escala Likert de 76 ítems. El mismo, antes de ser administrado, fue referido a la validación de cinco expertos, y sometido a una prueba piloto, donde obtuvo una confiabilidad de 0.804 . Considerándose como muy confiable.

La población estuvo compuesta por 75 arquitectos, escogidos como informantes o unidades de análisis, debido a que son los agentes principales en cuanto a la creación, planificación, ideación, control y ejecución del proyecto arquitectónico.

Estos profesionales declararon realizar su labor en el estado de Nuevo León, México, siendo esta la segunda entidad más importante del país, en cuanto a capital, aportado por empresas de construcción, al Producto Interno Bruto (PIB) Nacional, además de encontrarse oficinas de las principales empresas del diseño y la construcción.

Se utilizó para ello un muestreo no probabilístico, debido a que no existe un registro único de acceso público sobre el número de profesionales de la arquitectura en el país, ni en la región, relacionados al sector de la construcción.

Por lo que se aplicó la técnica de muestro en cadena por redes o bola de nieve, el cual consistió en identificar informantes o participantes claves, los cuales fueron contactados a través de la 
Universidad de Monterrey, la Cámara Mexicana de la Industria de la Construcción en Nuevo León, y el Colegio de Arquitectos; y estos a su vez condujeron a otros informantes, que proporcionaron datos que se iban incluyendo por la conexión de los primeros.

\section{Resultados}

El instrumento recolectó información relativa para analizar las técnicas de representación digital utilizadas para la representación del proyecto arquitectónico, señalando la frecuencia y los motivos de uso de los dibujos digitales en 2D, los dibujos digitales en 3D, la edición de imágenes/vídeos como instrumentos de comunicación, la realidad virtual y la realidad aumentada, así como las técnicas de fabricación digital.

Para el abordaje del trabajo se partió de lo expresado por Oliva (2016), quien considera que las técnicas de representación digital se asocian a procedimientos y procesos que buscan comunicar, planear, idear y, por ende, representar los elementos arquitectónicos, con el énfasis de que estos se realizan en ambientes o herramientas digitales, sin importar el momento o el medio de su aplicación, sino su función en cuanto al manejo de la imagen y el vídeo.

Con respecto a la primera dimensión de dibujos digitales 2D, la población encuestada refirió mayoritariamente la frecuencia de uso de los mismos para la representación del proyecto arquitectónico, donde $85.30 \%$ dio respuestas afirmativas, como se observa en la Figura 1.

En la misma línea, los resultados arrojados sobre los motivos de su uso, también inclinaron la balanza estadística positivamente sobre los tres criterios señalados por Muñoz (2016), que indican la relevancia de las proyecciones diédricas o planas para comprender, idear y comunicar el proyecto arquitectónico.

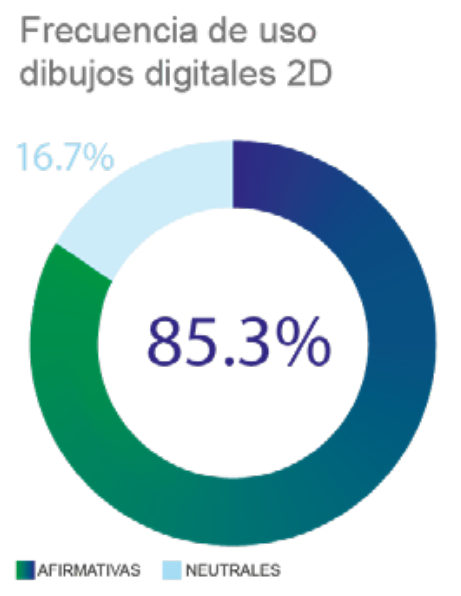

Figura 1. Frecuencia de uso de dibujos digitales $2 D$

Fuente: elaboración propia 
Los datos evidencian dicha afirmación, reflejando en los tres casos (comprender, idear, comunicar), con más de $90 \%$ de aprobación por parte de los informantes.

Estos resultados confirman lo mencionado por Muñoz (2016), que señala la importancia de los dibujos $2 \mathrm{D}$ en el proyecto arquitectónico, en cuanto fungen como un instrumento de control del mismo en todas sus fases de diseño, por ello sirven para su revisión y verificación, así como para su documentación y comunicación. De este modo puede afirmarse la preponderancia en el uso de estos como técnica digital de representación arquitectónica.

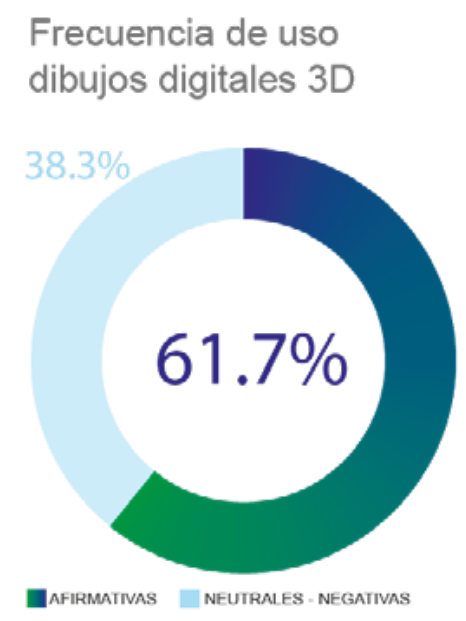

Figura 2. Frecuencia de uso de dibujos digitales $3 D$

Fuente: elaboración propia

En cuanto al uso de dibujos digitales en 3D o en tercera dimensión, los arquitectos infamantes se dividieron más equilibradamente en sus preferencias, aunque la opción de frecuencia de uso fue mayoritaria con $61.70 \%$, tal como se ve en la Figura 2; sin embargo, no es menos apreciable al resto de la estadística que lo consideró con posición neutral o negativa.

Sin embargo, a pesar de que la opción de proyecciones digitales en 3D tienen una tímida preferencia, los ítems que midieron las motivaciones de su uso, si apuntaron a reconocer su importancia y función en la representación del proyecto arquitectónico, donde la opinión positiva para cada caso, se mantuvo con $96 \%$, muy por encima del resto de las otras opciones.

De modo que estos resultados confirman lo planteado por Ching (2016) y Muñoz (2016), sobre las representaciones arquitectónicas en 3D, las cuales permiten mayor legibilidad del objeto diseñado, así como de facilitar cada etapa del proceso, conjugándose diversas variables en el proceso, más allá de lo formal y espacial.

Los datos mencionados hasta ahora, también confirman el privilegio que tienen los dibujos digitales 2D en la arquitectura sobre el manejo de 3D, y esto debido a que los métodos de proyecciones diédricos ortogonales, constituyen un valido patrimonio conceptual sobre el dibujo arquitectónico, convirtiéndose en la técnica prioritaria al momento del abordaje del tema arquitectónico. 
Por lo que las técnicas digitales del dibujo 2D, de alguna manera traspasaron o emularon el modo de trabajar analógico y los procesos implícitos en la representación, y con ellos, lograr el mismo resultado, ya que las plantas, cortes y fachadas siguen siendo la primera y mejor opción empleada por los arquitectos para el abordaje del proyecto.

Aunque también se valoren otros procedimientos tridimensionales, devenidos, mejorados y popularizados por la digitalización de la representación arquitectónica. En cuanto a la técnica de edición de imágenes y videos digitales, la población consultada se mantuvo neutral frente a su uso, indicando con ello que no la consideran una técnica prioritaria al momento de representar el objeto arquitectónico, dónde la opción neutral aglutinó $70.7 \%$ de las opciones, dividiendo drásticamente el resto de las demás tendencias.

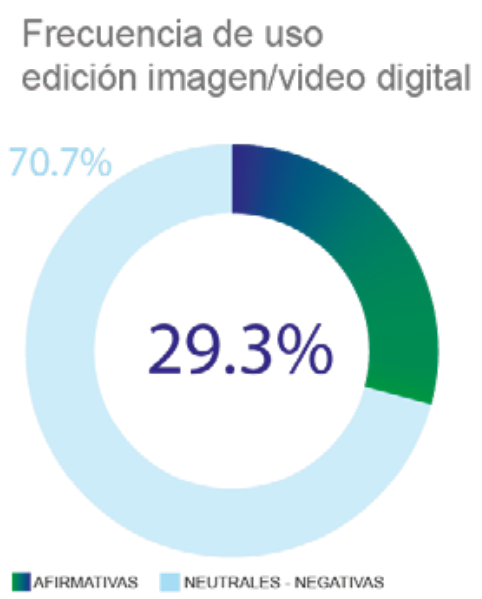

Figura 3. Frecuencia de uso edición imagen/video digital

Fuente: elaboración propia

Curiosamente este resultado coincide con la crítica y advertencia que hace Llopis (2018b) sobre el uso de la imagen digital, y como por la inclusión de diversas áreas gráficas y audiovisuales, al privilegiar la edición digital se puede incurrir en una banalización de la imagen como vehículo de expresión del edificio proyecto a convertirse en arquitectura.

Esta información de alguna manera también se puede explicar en la tradición misma de la arquitectura, ya que como señala Oliva (2016) estas técnicas no nacieron como parte del uso y aplicación de la digitalización en la arquitectura, sino que corresponden a otras disciplinas del diseño gráfico visual, como puede ser el cine o los video juegos, o la manipulación fotográfica, de modo que es razonable entender por qué los informantes se dividen en opinar sobre la importancia de estas.

El instrumento de recolección de datos se adentró aún más en esta temática consultando de manera diferenciada, por un lado, el uso de la imagen digital, y por otro el uso de los elementos multimedia (audio, vídeo, gifs, entre otras). 
Las respuestas mantuvieron las mismas tendencias y posiciones neutrales en ambos casos, en donde, pese a eso, se privilegia por alguna diferencia porcentual el uso de las imágenes.

La imagen digital además fue señalada por los informantes por sus tres características primordiales, según lo expresado por Oliva (2016), estas permiten mayores posibilidades de actuación durante las diferentes fases del diseño arquitectónico, ayuda además como herramienta de control y visualización del mismo, y, por ende, como instrumento válido para la documentación y comunicación del proyecto.

De modo que bien puede afirmarse que el principal motivo de uso las técnicas de edición de la imagen digital es su ayuda a la comunicación del proyecto arquitectónico; coincidiendo con lo planteado por Oliva (2016), quien señala que la imagen dota al proyecto, de un sentido más social y comercial como mensaje, más allá de lo estrictamente técnico y profesional.

En cuanto al uso de la realidad virtual y la realidad aumentada como técnica de representación del proyecto arquitectónico, los arquitectos encuestados respondieron categóricamente señalando la poca o nula aplicabilidad de dicha técnica en el proceso de diseño y comunicación de la arquitectónica, más del $50 \%$ de las opiniones apuntaron a una tendencia negativa, mientras que $32 \%$ se mantuvo neutral, y un marginal porcentaje de $6 \%$ no alcanzó para posicionar positivamente dicho aspecto, como se observa en la Figura 4.

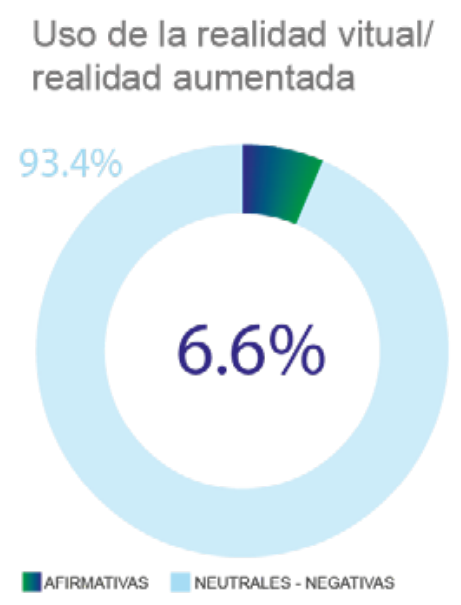

Figura 4. Uso de la realidad virtual/realidad aumentada

Fuente: elaboración propia

Los datos obtenidos pueden relacionarse con lo mencionado anteriormente, ya que Oliva (2016) señalaba que dichas técnicas no son propias de la arquitectura, sino que han sido incorporadas de manera entusiasta durante el proceso de digitalización de la misma, por ello no constituyen una prioridad entre los profesionales, que aunque reconocen su beneficio, no terminan por acogerlas como propia de su hacer. 
Lo expresado, concuerda con la postura de Picon (2006), quien alertaba sobre el riesgo de la virtualización de la arquitectura, que podría desembocar en la desmaterialización de la misma, es decir, en trastocar el sentido profundo de que toda arquitectura lleva implícito un proceso de diseño, construcción y materialización real, por lo que aunque lo que se muestre mediante realidad virtual o aumentada, parezca arquitectura, desde el punto de vista material no lo sea, sino una simple simulación.

La neutralidad del peso estadístico, de $32 \%$ de los encuestados, puede comprenderse, sin embargo, desde la óptica de Rodríguez et al. (2016), quienes señalan que la realidad virtual y la realidad aumentada son una técnica más, que no busca sustituir o invalidad a las otras, sino más bien complementarlas, de modo que sea un medio que aporta riqueza al proceso de diseño arquitectónico, y, por ende, a su representación.

Dicha polarización en los resultados evidencia lo que ya se anticipaba en la discusión teórica del presente estudio, por una parte, una corriente que cuestiona la virtualidad de la arquitectura como se refleja en los comentarios de Picon (2006), y en contraparte lo que señalan Rodríguez et al. (2016), quienes, al contrario, ven en ello una novedosa y útil técnica de diseño, representación y comunicación del proyecto.

Cómo última etapa se abordó el uso de la fabricación digital, como técnica de representación para el proyecto arquitectónico, de los informantes consultados, un poco más de 30\% (Figura 5) dijeron usarla en su proceso de diseño profesional, mientras que el resto de la balanza estadística se inclinó con $25 \%$ de manera neutral y el resto $45 \%$, negando el uso de las mismas.

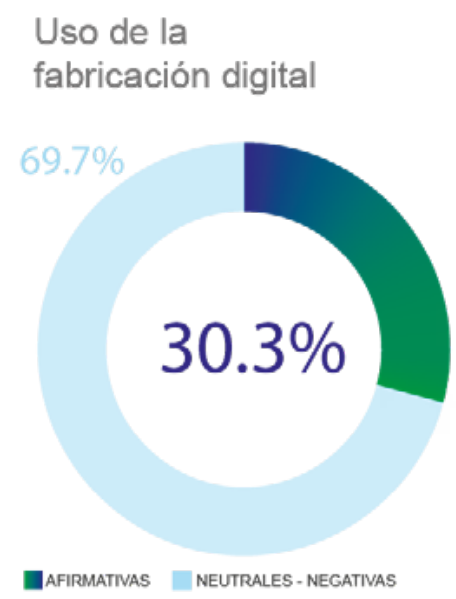

Figura 5. Uso de la fabricación digital

Fuente: elaboración propia

Estos resultados, de alguna manera confirman lo que señalan Ferrándiz et al. (2018), quienes ven a la fabricación digital como una disciplina en expansión y con aplicabilidad en diversas áreas del diseño, en donde se incluye la arquitectura. Lo mismo que las técnicas anteriores, esta no 
surge como una expresión propia para el diseño de edificaciones, sino que es introducida por los entusiastas de la digitalización.

La diferencia de esta técnica con la mencionada anteriormente (realidad virtual/aumentada) está, en que aquí sí será de importancia capital el proceso de materialización, y, por ende, de la ejecución de la arquitectura como disciplina de la construcción.

Lo notorio de los resultados obtenidos es que a pesar de que buena parte de los arquitectos encuestados dicen no usar la fabricación digital (o al menos no frecuentemente), sí reconocen sus beneficios.

Estos datos se añaden a lo sostenido por Robles (2016), en cuanto a que la fabricación digital permite que el arquitecto experimente con la materialidad del objeto de su trabajo los materiales, por ello no son una referencia en la representación, sino que forman parte de esta; al mismo tiempo, dicha experimentación permite la resolución de formas complejas y generativas, logradas por la digitalización, de modo que dicha técnica explora nuevos procesos creativos, asociados al hacer propio del diseño.

Al respecto, se consultó sobre cuál de las técnicas de fabricación digital supone la preferencia de los arquitectos encuestados, resaltando en los resultados dos principalmente:

- La técnica de moldeado, basada en el uso de moldes machos y hembras para la generación de formas.

- La técnica de seccionado, lograda mediante cortes laser en CNC de piezas que luego se arman. 


\section{Técnicas digitales aplicadas \\ en la representación arquitectónica}

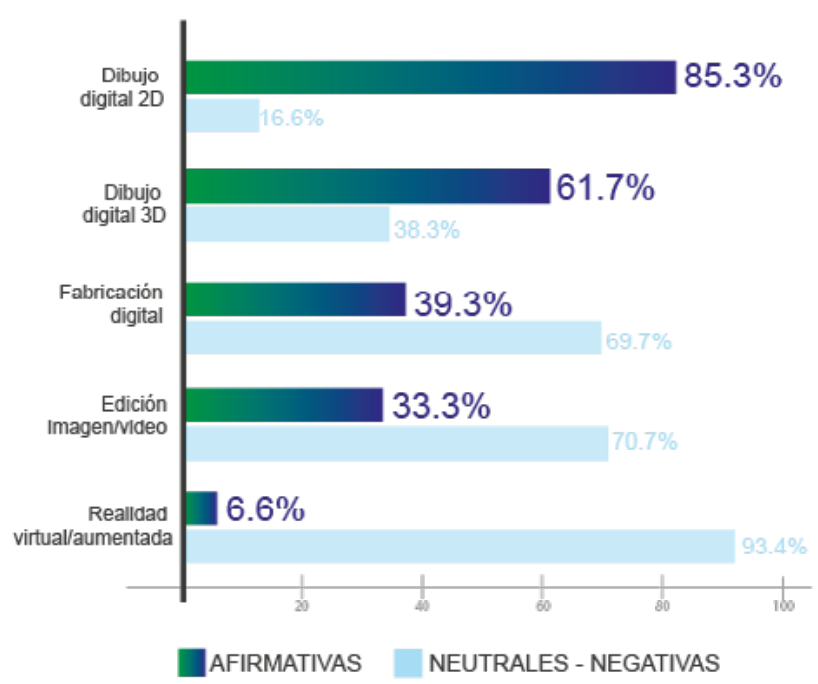

Figura 6. Técnicas digitales aplicadas en la representación arquitectónica

Fuente: elaboración propia

Los resultados presentados muestran una preferencia evidente de algunas técnicas sobre otras; sin embargo, estas no deben ser del todo descartables, ya que están presente en la referencia teórica consultada, y de alguna manera responden a las posibles oportunidades a desarrollarse y expandirse en materia de representación arquitectónica, imbuida en la digitalización.

\section{Conclusiones}

Las técnicas digitales de representación aplicadas en el proyecto arquitectónico en Nuevo León, México están constituidas por el uso del dibujo digital 2D y el dibujo digital 3D. Siendo la primera, la principal expresión de comunicación, documentación para la revisión y validación del proyecto arquitectónico. Seguida a esta se encuentra el uso del dibujo digital 3D, sobre todo en lo relacionado a que estas permiten la visualización de las formas arquitectónicas.

En segundo nivel de uso o jerarquía, se encuentran las técnicas de edición digital de imágenes y vídeos, así como la fabricación digital aplicadas a la representación del proyecto arquitectónico.

Las técnicas de realidad virtual y aumentada no son consideradas como parte del proceso de representación del proyecto de arquitectura, y esto quizás a que su aplicación requiere de cierta especialización, exploradas, según la bibliografía consultada, solo a nivel académico y no en ámbitos profesionales. 
La representación arquitectónica, por tanto, aunque se encuentra imbuida en las tecnologías digitales, subsiste en una etapa en transición y adaptación, en donde el paso de la digitalización a la virtualización del objeto diseñado, sigue siendo un camino en exploración.

La investigación demostró que la práctica de la arquitectura transita todavía un camino de adaptación hacías las tecnologías digitales, y por ello es necesario seguir profundizando en su estudio y efectividad. Esto se demuestra en que el mayor porcentaje de aprobación se lo llevan los dibujos digitales 2D, los cuales se realizan con la misma lógica de hace seis siglos, con la diferencia de un cambio de instrumentación que pasó de lo analógico a lo digital.

No es tarea fácil lograr el cambio, ya que la práctica profesional, desde tiempos inmemorables, se ha visto asociada al aspecto artesanal, al pensar, hacer, diseñar y materializar con las propias manos. Y es en este punto en donde se encuentra el mayor cambio de paradigma, un cambio que va más allá de la mera instrumentación, del cómo hacer arquitectura: las tecnologías digitales están influyendo en el cómo repensar y recrear (como acto de creación de algo nuevo) la arquitectura, y he allí el gran reto.

Adicionalmente, sigue prevaleciendo la idea y el sentido de la comunicación de la representación de la arquitectura como lenguaje, y como mensaje.

Los dibujos digitales en 2D y en 3D mantienen por tanto el patrimonio heredado de siglos precedentes, en cuanto a técnicas de expresión, sólo que ahora se hacen en escenarios que facilitan su transmisión y corrección. 


\section{Referencias}

Abondano, D. (2018). De la arquitectura moderna a la arquitectura digital La influencia de la revolución industrial y la revolución informacional en la producción y la cultura arquitectónica. [Tesis Doctoral, Universitat Ramon Llull]

Centro de Estudios Económicos del Sector de la Construcción. (2018). Situación Actual y Perspectivas de la Industria de la Construcción en México 2018 - 2019. https://www.cmic.org.mx/cmic/ceesco/2019/SITUACl\%C3\%93N\%20Y\%20PERSPECTIVAS\%20DE\%20LA\%20ACTIVIDAD\%20PRODUCTIVA\%20DE\%20 LA\%20\%20INDUSTRIA\%20DE\%20LA\%20CONSTRUCCI\%C3\%93N \%20DICIEMBRE\%202018 CEESCO.pdf

Ching, F. D. K. (2016). Manual de dibujo arquitectónico. Editorial Gustavo Gili.

Ching, F. D. K., \& Juroszek, S. P. (2012). Dibujo y proyecto. Editorial Gustavo Gili.

Etchegaray, F. (2017). Representación digital en las comunicaciones de proyectos arquitectónicos académicos - estudio de caso. [Tesis Doctoral, Universitat Politècnica de Catalunya]. UPCommons. http://hdl.handle. net/2117/96141

Ferrándiz Bou, S.; López Martínez, J.; Samper Madrigal, MD.; García García, D.; Ferri Azor, JM. (2018). Prácticas de prototipos avanzados. Editorial Universitat Politècnica de València. http://hdl.handle.net/10251/106919

Frogheri, D. (2018). Entre el pensar y el hacer avanzados. [Tesis doctoral, Universitat Politècnica de Catalunya].

Hernández, R., y Fernández, C., y Baptista, P. (2014). Metodología de la investigación (6ta. Ed.). Editorial McGraw-Hill.

Jorquera, A. (2017). Jorquera Ortega, A. (2016). Fabricación digital: Introducción al modelado e impresión 3D. Ministerio de Educación, Cultura y Deporte.

KPMG International. (2016). Building a technology advantage. Harnessing the potential of technology to improve the performance of major projects. Global Construction Survey 2016. https://assets.kpmg/content/dam/ $\mathrm{kpmg} / \mathrm{mx} / \mathrm{pdf} / 2016 / 12 / \mathrm{Global}-$ construction-survey-2016.pdf

Llopis, J. V. (2018a). Entre representación y simulación. Un cambio de paradigma en el dibujo arquitectónico contemporáneo. Revista EGA Expresión Gráfica Arquitectónica, 23(34), 180-193. https://doi.org/10.4995/ ega.2018.10860

Llopis, J. V. (2018b). Dibujo y arquitectura en la era digital: reflexiones sobre el dibujo arquitectónico contemporáneo. Universitat Politècnica de València. 
Montaner, J. (2015). La condición contemporánea de la arquitectura. Editorial Gustavo Gili GG.

Muñoz, A. (2016). El proyecto de arquitectura: concepto, proceso y representación (2da. Edición). Editorial Reverté.

Navarro Delgado, I., \& Fonseca Escudero, D. (2017). Nuevas tecnologías de visualización para mejorar la representación de arquitectura en la educación. ACE: architecture, city and environment, 12(34), 219-238. http://hdl.handle.net/2117/106069

Oliva, R. (2016). Avances tecnológicos en representación gráfica su influencia en el diseño arquitectónico. [Tesis doctoral, Universitat Politècnica de Catalunya] http://hdl.handle.net/2117/98088

Pecoraio, S. (2017). MF0638 Representaciones de construcción. Editorial Cano Pina.

Picon, A. (2006). Arquitectura y virtualidad: Hacia una nueva condición material. ARQ, (63), 10-15. https://doi. org/10.4067/S0717-69962006000200002

Robles, A. (2016). Fabricación digital en arquitectura: técnicas, recursos y conocimiento material. Revista Digital Universitaria, 17(8) http://www.revista.unam.mx/vol.17/num8/art61/

Rodríguez, M. A., Desvaux, N. G., \& Tordesillas, A. Á. (2016). De la mente al papel. Nuevas técnicas aplicadas al dibujo de arquitectura. In El arquitecto, de la tradición al siglo XXI: docencia e investigación en expresión gráfica arquitectónica (pp. 453-460). Fundación General de Alcalá. https://www.researchgate.net/publication/311487766 De la mente al papel Nuevas tecnicas aplicadas al dibujo de arquitectura

Sainz, J. (2009). El dibujo de arquitectura: Teoría e historia de un lenguaje gráfico (3era. Ed.). Editorial Reverté.

Strike, J. (2018). De la construcción a los proyectos: La influencia de las nuevas técnicas en el diseño arquitectónico, 1700-2000. Editorial Reverté. 
Copyright (c) 2021 Raymundo Alberto Portillo Ríos

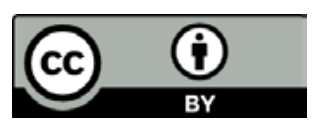

Este texto está protegido bajo una licencia internacional Creative Commons 4.0.

Usted es libre para Compartir-copiar y redistribuir el material en cualquier medio o formato

- y Adaptar el documento - remezclar, transformar y crear a partir del material-para cualquier propósito, incluso para fines comerciales, siempre que cumpla las condiciones de Atribución. Usted debe dar crédito a la obra original de manera adecuada, proporcionar un enlace a la licencia, e indicar si se han realizado cambios. Puede hacerlo en cualquier forma razonable, pero no de forma tal que sugiera que tiene el apoyo del licenciante o lo recibe por el uso que hace de la obra.

Resumen de licencia - Texto completo de la licencia 